on clothing. Infective larvae hatch in two days. These penetrate human skin on contact, causing the characteristic furuncular lesions recognisable by the posterior tip of the larva barely visible at the centre. The most effective management is to cover the lesion with petroleum jelly. Deprived of air, the larva partly emerges and can then be easily expressed with digital pressure.

There has been one previous report of this infection known to have been acquired outside the recognised distribution of the fly; this occurred in a British woman who had returned from holiday in Spain. ${ }^{3}$ The only explanation that we can offer for the infection occurring in these children in northern Europe is that their father, who had made several recent visits to Africa on business, may have brought back eggs from a tumbu fly among his possessions.

This curious occurrence, once again, illustrates the weakness of rigidly maintaining our geographical preconceptions about the incidence of infectious disease, as further evidenced by the recent reports of "airport malaria."'

1 Calvert H. Myiasis from the tumbu fly: two cases reported. $\operatorname{Br}$ Med $\mathcal{F} 1961$; $1513-4$.

2 Wildy GS, Glover SC. Myiasis due to tumbu fly larva. Lancet 1982;ii:1130-1.

Laurence BR, Herman FG. Tumbu fly (Cordylobia) infection outside Africa.

Trans R Soc Trop Med Hyg 1973;67:888.

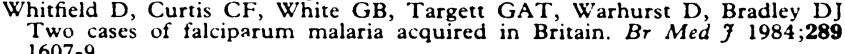

(Accepted 18 fanuary 1985)

Hospital for Tropical Diseases, London NW1 OPE

G G BAILY, MRCP, medical registrar

A H MOODY, FIMLS, senior chief medical laboratory scientific officer, department of pathology

Correspondence to: Dr G G Baily.

\section{Decreased intraperitoneal insulin requirements during peritonitis on continuous ambulatory peritoneal dialysis}

Continuous ambulatory peritoneal dialysis is being increasingly used in the management of the final stage of chronic renal failure due to diabetes mellitus. One of the principal advantages over haemodialysis is the excellent control of blood glucose which can be achieved with regular intraperitoneal insulin administered with the dialysate; usually four times daily. We report considerable reductions in the requirements for intraperitoneal insulin during severe peritonitis, which most patients using continuous ambulatory peritoneal dialysis experience about twice a year."

\section{Methods and results}

We studied six patients in the final stage of chronic renal failure due to diabetes mellitus during an episode of severe bacterial peritonitis. This was diagnosed by abdominal pain, turbid effluent, dialysate white cell count greater than $100 \mu \mathrm{l}$, and positive bacterial culture (Staphylococcus epidermidis in five cases and Staph aureus in one). All patients were treated with cephalothin intraperitoneally at a dose of $500 \mathrm{mg} 1$ of dialysate for 10 days, by which time symptoms and signs had resolved completely; the mean time to clear fluid was five days. Patients were instructed to maintain their blood glucose within the range $7-13 \mathrm{mmol} / 126-234 \mathrm{mg} / \mathrm{lO} \mathrm{ml})$ by checking a capillary blood sample and using a sliding scale of neutral insulin injection administered intraperitoneally with the dialysate at each change of bag.

All patients required considerably less insulin during the acute phase of peritonitis, especially in the first three days (see table). Two patients became profoundly hypoglycaemic, both on day three and presented in coma. By the 10th day after the onset of infection insulin requirements had virtually returned to normal.

\section{Comment}

During severe infections most diabetic patients exhibit increased insulin requirements due to the resulting catabolic state. Clearly, this practice would have disastrous consequences during an episode of peritonitis in diabetic patients using continuous dialysis, who receive insulin by the intraperitoneal route. Many of these patients exhibit
Total daily requirement for insulin $(I U)$ during bacterial peritonitis. Figures in parentheses represent percentage amount of normal daily insulin dose

\begin{tabular}{cccccc}
\hline Case No & $\begin{array}{c}\text { Usual requirements } \\
\text { for insulin }\end{array}$ & Day 2 & Day 4 & Day 7 & Day 10 \\
\hline 1 & 78 & $60(77)$ & $58(74)$ & $70(90)$ & $80(103)$ \\
2 & 110 & $70(64)$ & $100(91)$ & $100(91)$ & $106(96)$ \\
3 & 158 & $120(76)$ & $120(76)$ & $136(86)$ & $150(95)$ \\
4 & 136 & $110(81)$ & $130(96)$ & $136(100)$ & $136(100)$ \\
5 & 146 & $108(74)$ & $126(86)$ & $126(86)$ & $146(100)$ \\
6 & 108 & $90(83)$ & $102(94)$ & $108(100)$ & $108(100)$ \\
\hline
\end{tabular}

pronounced autonomic neuropathy, which reflects the advanced nature of the underlying disease, with little or no awareness of impending hypoglycaemia. Coma may be the presenting symptom.

Reduced intake of carbohydrate due to anorexia is, therefore, unlikely to explain the fall in intraperitoneal insulin requirements in these catabolic patients; the principal reason is probably the increased absorption of insulin due to mesothelial damage, an occurrence also described with a number of antibiotics administered intraperitoneally during peritonitis. ${ }^{3}$

For peritonitis in diabetic patients using continuous dialysis we recommend that regular doses of intraperitoneal insulin are reduced and that monitoring of blood sugar is performed before every change of bag. Where possible patients should not be left alone, especially if they have diminished awareness of hypoglycaemic symptoms, as coma might ensue.

1 Legrain M, Shahat YE, Rottenbourg J, et al. CAPD versus other treatment modalities in end stage diabetic nephropathy. In: Gahl GM, Kessel M, Nolph Amsterdam: Excerpta Medica, 1981.

2 Everett ED. Diagnosis, prevention and treatment of peritonitis. Peritoneal Dialysis Bulletin 1984;4:139-42.

3 Thomas V, Adam D. Efficacy and tolerability during long term administration of azlocillin with CAPD. MMW 1984;125:272-5

(Accepted 13 February 1985)

Renal Unit and Department of Medicine, Royal Infirmary, Glasgow G4 OSF

I S HENDERSON, BSC, MRCP, senior registrar

K R PATTERSON, MRCP, senior registrar

A C T LEUNG, MRCP, registrar

Correspondence to: Dr I S Henderson.

\section{"Missed pill" conception: fact or fiction?}

When pregnancy occurs during the use of the combined low dose oral contraceptive pill the patient often insists that she has missed taking only one, or at most two, of the pills. As the combined oral contraceptive pill suppresses gonadotrophin production and therefore folliculogenesis, ${ }^{1}$ the clinician is invariably sceptical: ovulation occurring within 48 hours of removal of the oestrogen suppression of pituitary gonadotrophin production seems highly unlikely. We report the demonstration of ovarian folliculogenesis during the seven day pill withdrawal in 28 day pill cycles, which makes the genuine occurrence of "missed pill" conceptions seem less mythical.

\section{Patients and results}

We studied 19 healthy nulliparous subjects aged from 20 to 30 years who were using the low dose combined oral contraceptive pill; all gave informed consent. All had normal menstrual histories before oral contraceptive use. They had been on treatment for at least three months and had regular monthly withdrawal bleeds.

Ultrasonographic examination of the ovaries was performed on the last day of one pill pack (day 21), on the last "pill free" day (day 28), and on the seventh day of the next pill pack (day 7). An Elscint Dynex sector scanner, with a $3.5 \mathrm{MHz}$ probe, was used which is capable of measuring down to $1.5 \mathrm{~mm}$.

The results are shown in the table along with the proprietary names of the oral contraceptives used by each subject. All subjects showed some ovarian follicular activity by the last day of the pill free phase and half developed multiple follicles with a dominant follicular diameter of $7 \mathrm{~mm}$ or greater, the diameter seen on day 7 of the normal cycle." Continuation of the gonadotrophin stimulation of these dominant follicles would have led to ovulation. ${ }^{3}$ By the seventh day of the new pill pack the follicular ap- 